\section{Commentary: Seal the calcium}

\author{
Juan A. Crestanello, MD
}

The management of patients with mitral annular calcification (MAC) is challenging. ${ }^{1}$ Options for its treatment include (1) conventional surgery with or without annular decalcification, ${ }^{1}(2)$ transcatheter mitral valve replacement, either trans-septal or direct trans-atrial transcatheter mitral valve replacement (dTMVR), ${ }^{2-5}$ and (3) extra-anatomic bypass. ${ }^{6}$ MAC is usually associated with small hypertrophic ventricles increasing the risk of left ventricular outflow tract (LVOT) obstruction with transeptal transcatheter mitral valve replacement. ${ }^{5}$ A traditional surgical approach to mitral valve replacement is technically challenging by the placement of the annular stiches through the calcified annulus or leaflets and the risk of disruption of the atrioventricular continuity but has the advantage of allowing for the resection of the anterior leaflet of the mitral valve. ${ }^{1} \mathrm{~A}$ dTMVR using a transcatheter balloon-expandable aortic prosthesis has several advantages: (1) it allows for the radial force of the stent to secure the valve in place minimizing the need for annular stitches through the calcified anulus; (2) it allows for the resection of the anterior leaflet of the mitral valve minimizing the risk of LVOT obstruction; and (3) it allows for the performance of a septal myectomy to further open the LVOT if necessary. ${ }^{2-4}$

However, incomplete sealing between the stent and the mitral annulus may result in perivalvular leak. Several techniques have been described to minimize perivalvular leak including the suture of a felt strip to the stent of the SAPIEN valve (Edwards Lifesciences, Irvine, Calif) or as in this case report the suturing to the annulus. ${ }^{2-4,7}$ Both techniques are successful in reducing the incidence of perivalvular leak, and there are no data to judge the advantage of one over

\footnotetext{
From the Department of Cardiovascular Surgery, Mayo Clinic, Rochester, Minn. Disclosures: The author reported no conflicts of interest.

The Journal policy requires editors and reviewers to disclose conflicts of interest and to decline handling or reviewing manuscripts for which they may have a conflict of interest. The editors and reviewers of this article have no conflicts of interest.

Received for publication Jan 14, 2020; revisions received Jan 14, 2020; accepted for publication Feb 2, 2020; available ahead of print Feb 27, 2020

Address for reprints: Juan A. Crestanello, MD, Department of Cardiovascular Surgery, Mayo Clinic, 200 First St SW, Rochester, MN 55905 (E-mail: crestanello. juan@mayo.edu).

JTCVS Techniques 2020;2:41-2

2666-2507

Copyright (C) 2020 The Authors. Published by Elsevier Inc. on behalf of The American Association for Thoracic Surgery. This is an open access article under the CC BY-NCND license (http://creativecommons.org/licenses/by-nc-nd/4.0/).

https://doi.org/10.1016/j.xjtc.2020.02.017
}

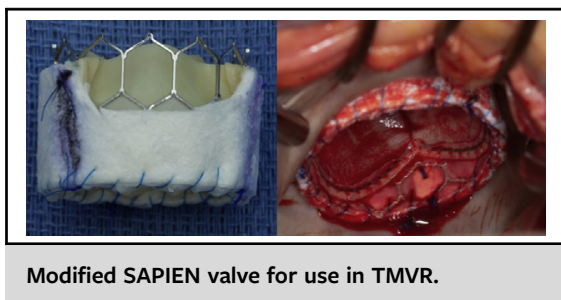

CENTRAL MESSAGE

TMVR is a valid alternative in patients with MAC.

the other. This author prefers the sewing to the stent frame with scalloping the leaflet facing the anterior leaflet of the mitral valve (Figure 1). The scalloped portion is then oriented toward the anterior mitral annulus. ${ }^{2}$

The combination of MAC with other hemodynamically significant valve pathologies is a formidable technical challenge. Careful decisions should be made in terms of the severity of the mitral valve disease, the need to address the mitral valve, and the technique for valve replacement.

In this issue of the Journal, Felmly and colleagues ${ }^{7}$ addressed a case of combined aortic and mitral valve disease using a hybrid approach combining robotic dTMVR under cardiopulmonary bypass followed by traditional transfemoral transcatheter aortic valve replacement. Although this case represents a remarkable technical and logistical accomplishment that will become more common in the future, several points are worth of comment.

First, patients with MAC often have significant diastolic dysfunction and left atrial noncompliance with falsely elevated gradients across the mitral valve. Therefore, it is imperative that a thorough invasive hemodynamic assessment is performed to confirm the severity of the mitral stenosis. ${ }^{8}$

Second, the mitral calcification in this patient was relatively thin, appeared limited to the leaflets, and, as seen in Video 1 of their article, the annular stiches were placed with ease. Given this calcium distribution, it is likely that a conventional mitral valve replacement could have been performed.

Third, the authors used a SAPIEN S3 valve, which has a short skirt. The SAPIEN S3 Ultra valve with its taller more textured skirt may seal better avoiding the need of the felt strip. It is imperative that the skirt is placed in the annular plane to maximize sealing.

Fourth, the preoperative evaluation of the LVOT with cardiac computed tomography and the estimation of the risk of LVOT obstruction with the virtual valve in place should be performed preoperatively to assess the risk of LVOT and help guide the treatment technique. 


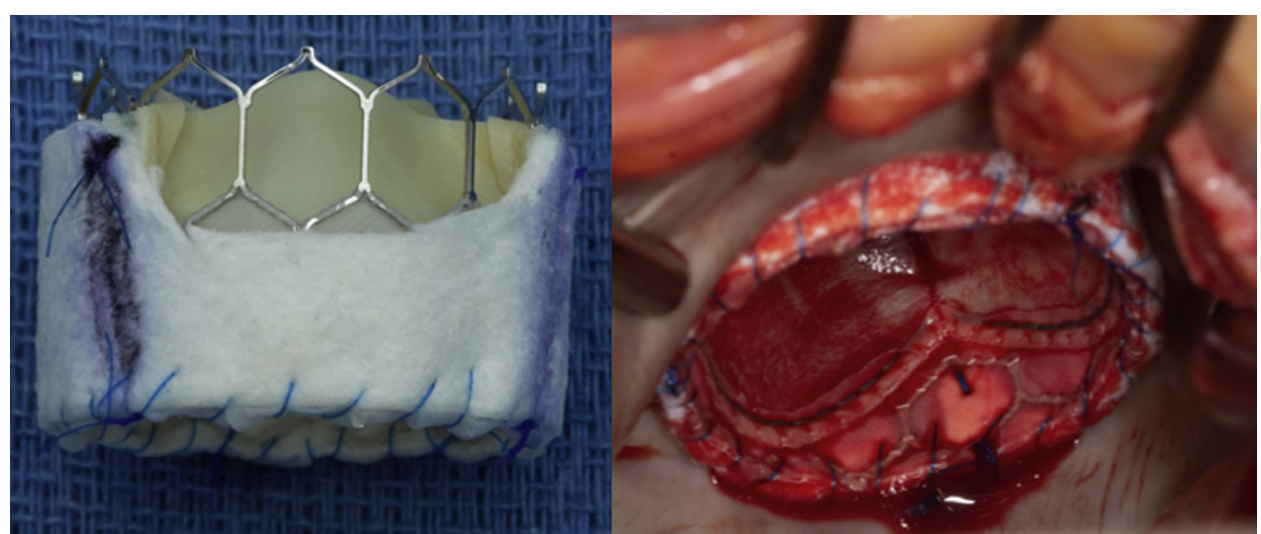

FIGURE 1. Left: Modified Sapien valve (Edwards Lifesciences, Irvine, Calif) with a felt strip sewn outside the stent. The felt strip is scalloped at the level of the anterior leaflet to avoid left ventricular outflow tract obstruction. Right: expanded modified Sapien valve in the mitral position.

Finally, the hybrid approach to valvular heart disease is an attractive alternative for patients who are not optimal candidates to address all the valve lesions with transcatheter or surgical intervention. This is a promising and fertile area for research that will lead to advancement of our specialty and benefit to our patients.

\section{References}

1. Saran N, Greason KL, Schaff HV, Cicek SM, Daly RC, Maltais S, et al. Does mitral valve calcium in patients undergoing mitral valve replacement portend worse survival? Ann Thorac Surg. 2019;107:444-52.

2. Bernabei A, Eleid MF, Guerrero M, Crestanello JA. Modifications of transatrial transcatheter mitral valve replacement technique. CTSNet. 2019; https://doi.org/ 10.25373/ctsnet.10293386.
3. Russell HM, Guerrero ME, Salinger MH, Manzuk MA, Pursnani AK, Wang D, et al. Open atrial transcatheter mitral valve replacement in patients with mitral annular calcification. J Am Coll Cardiol. 2018;72:1437-48.

4. El Sabbagh A, Eleid MF, Foley TA, Al-Hijji MA, Daly RC, Rihal CS, et al. Direct transatrial implantation of balloon-expandable valve for mitral stenosis with severe annular calcifications: early experience and lessons learned. Eur J Cardiothorac Surg. 2018;53:162-9.

5. Guerrero M, Urena M, Himbert D, Wang DD, Eleid M, Kodali S, et al. 1-year outcomes of transcatheter mitral valve replacement in patients with severe mitral annular calcification. J Am Coll Cardiol. 2018;71:1841-53.

6. Said SM, Schaff HV. An alternate approach to valve replacement in patients with mitral stenosis and severely calcified annulus. J Thorac Cardiovasc Surg. 2014; 147:e76-8

7. Felmly LM, Johnson SD, Steinberg D, Katz MR. Hybrid double-valve replacement. J Thorac Cardiovasc Surg Tech. 2020;2:36-7.

8. Reddy YNV, Murgo JP, Nishimura RA. Complexity of defining severe "stenosis" from mitral annular calcification. Circulation. 2019;140:523-5. 